\title{
ANALISIS KINERJA JALAN PROTOKOL KOTA BANDAR LAMPUNG (Studi Kasus Jalan RA Kartini Kota Bandar Lampung)
}

\author{
Farida Juwita \\ Dosen Fakultas Teknik sipil Universitas Sang Bumi Ruwa Jurai
}

\begin{abstract}
Abstrak
Masalah kemacetan di Jalan RA Kartini yang merupakan jalan satu arah terutama dirasakan pada jam-jam sibuk, baik pagi maupun sore hari, yaitu saat orang bepergian dari rumah ke tempat bekerja, sekolah atau aktivitas lainnya, dan juga saat mereka pulang kembali ke rumahnya masing-masing.Tujuan penelitian ini adalah Mengidentifikasi kinerja jalan Kartini terhadap keberadaan simpang dan pusat kegiatan di sepanjang ruas jalan RA Kartini dan Memberikan gambaran kinerja jalan RA Kartini berdasarkan tingkat pelayanan jalan (level of service).Penelitian analisis kinerja jalan ini dilakukan di Jalan RA Kartini Kota Bandar Lampung.Metode pengumpulan data yang akan digunakan dalam penyusunan penelitian ini adalah pengumpulan data melalui observasi lapangan dan observasi tidak langsung.Jalan Raden Ajeng Kartini Kota Bandar Lampung termasuk jalan fungsi arteri sekunder dengan kelas Jalan Kota. Panjang jalan ini yaitu 1,20 km dengan lebar $14 \mathrm{~m}$. Jalan RA Kartini terdiri dari 4 (empat) lajur 1 (satu) arah dengan lebar tiap lajur adalah 3,5 $\mathrm{m}$. Jalan ini tidak memiliki bahu dan hanya di beberapa titik dilengkapi oleh trotoar dengan lebar 1,5 $\mathrm{m}$ serta dilengkapi kareb. Di sepanjang jalan ini merupakan pusat perdangangan, perbankan, kawasan perhotelan, sehingga peran jalan ini begitu penting bagi masyarakat Kota Bandar Lampung.Setiap hari jalan RA Kartini dipenuhi oleh kendaraan yang melintas satu arah.
\end{abstract}

Kinerja : kinerja, protokol kota

\section{ANALYSIS OF ROAD PERFORMANCE PROTOCOL CITY BANDAR LAMPUNG (Case Study of Jalan RA Kartini Kota Bandar Lampung)}

\author{
Farida Juwita \\ Lecturer of Civil Engineering Faculty of Sang Bumi University Ruwa Jurai
}

\begin{abstract}
The problem of congestion on Jalan RA Kartini which is a one-way street that is focused on rush hour, both morning and evening, that is when people travel from home to work, school or other activities, and also when they return to their respective world. this study is to identify the performance of Kartini road to the proximity and activity center along RA Kartini road and detail detail of RA Kartini performance based on road service level. The implementation level is done in Jalan RA Kartini Kota Bandar Lampung. Data method that will be used in the preparation of this research is data data through field observation and indirect observation. Raden Ajeng Kartini Street Bandar Lampung City includes secondary arterial function road with street class Kota. The length of this road is $1.20 \mathrm{~km}$ with a width of $14 \mathrm{~m}$. RA Kartini Road consists of 4 (four) lanes 1 (one) direction with the width of each lane is $3.5 \mathrm{~m}$. This road has no shoulders and only at some point is equipped by a sidewalk with a width of $1.5 \mathrm{~m}$ and equipped with kareb. Along this road is the center of trade, train, hotel area, so the role of this road is very important for the people of Bandar Lampung.Setiap day RA Kartini street full of vehicles passing one direction.
\end{abstract}

Performance: performance, city protocol 


\section{Pendahuluan}

\subsection{Latar Belakang}

Berdasarkan Peraturan Daerah Kota Bandar Lampung Tahun 2011 tentang Rencana Tata Ruang Wilayah Kota Bandar Lampung 2011 - 2030, Jalan RA Kartini di Kota Bandar Lampung merupakan yang merupakan Jalan Arteri Sekunder. Masalah kemacetan di Jalan RA Kartini yang merupakan jalan satu arah terutama dirasakan pada jam-jam sibuk, baik pagi maupun sore hari, yaitu saat orang bepergian dari rumah ke tempat bekerja, sekolah atau aktivitas lainnya, dan juga saat mereka pulang kembali ke rumahnya masing-masing. Perubahan jalur kendaraan umum angkot yang memotong jalan RA Kartini menuju Jalan Raden Intan via jalan Pemuda juga merupakan salah satu penyebab tundaan yang terjadi di jalan tersebut karena banyak angkutan kota yang memotong jalan dengan arah diagonal sehingga menghambat laju pergerakan kendaraan lain. Sehubungan dengan permasalahan di atas, diperlukan kajian kinerja jalan Kartini berdasarkan kondisi aktual lalu lintas di jalan tersebut pada saat ini.

\subsection{Rumusan Masalah}

Berdasarkan latar belakang yang telah disebutkan di atas, maka rumusan masalah disampaikan sebagai berikut : a. Bagaimana kineja ruas jalan RA Kartini Kota Bandar Lampung saat ini?

b. Apakah ada pengaruh sistem skenario pengalihan lalu lintas terhadap kinerja ruas Jalan RA Kartini?

\subsection{Tujuan Penelitian}

Tujuan penelitian ini adalah sebagai berikut : Mengidentifikasi kinerja jalan Kartini terhadap keberadaan simpang dan pusat kegiatan di sepanjang ruas jalan RA Kartini

\subsection{Manfaat Penelitian}

Hasil penelitian ini diharapkan dapat memberikan manfaat:

a. mengetahui analisis kinerja jalan protokol di Kota Bandar Lampung khususnya jalan RA Kartini

\subsection{Batasan Masalah}

Batasan masalah yang menjadi fokus pada skripsi ini adalah :

a. Kegiatan atau aktifitas yang digunakan sebagai obyek pembahasan adalah ruas Jalan RA Kartini Kota Bandar Lampung

\section{Tinjauan Pustaka}

\subsection{Jalan}

Berdasarkan Peraturan Pemerintah No. 34 Tahun 2006, bahwa Jalan adalah prasarana transportasi darat yang meliputi 
segala bagian jalan, termasuk bangunan pelengkap dan perlengkapannya yang diperuntukkan bagi pergerakan lalulintas, yang berada pada permukaan tanah, di atas permukaan tanah, di bawah permukaan tanah dan/atau air, serta di atas permukaan air, kecuali jalan kereta api, jalan lori, dan jalan kabel.

\subsection{Klasifikasi Jalan Menurut Fungsi}

Berdasarkan fungsinya, jalan dapat dibagi menjadi 3, yaitu :
a. Jalan Arteri
b. Jalan Kolektor
c. Jalan Lokal

\subsection{Sistem Jaringan Jalan}

Jaringan jalan merupakan satu kesatuan sistem terdiri dari sistem jaringan jalan primer dan sistem jaringan jalan sekunder yang terjalin dalam hubungan hirarki

\subsubsection{Sistem Jaringan Jalan Primer}

Adapun kriteria sistem jaringan jalan primer adalah sebagai berikut :
a. Sistem jaringan jalan primer
b. Jaringan jalan primer
c. Jalan Arteri Primer
d. Jalan Kolektor
e. Jalan Lokal Primer

\subsubsection{Sistem Jaringan Jalan Sekunder}

Adapun kriteria sistem jaringan jalan primer adalah sebagai berikut :
a. Sistem jaringan
b. Jalan Arteri Sekunder
c. Jalan Kolektor Sekunder

Tabel di bawah ini menunjukkan Hubungan Antara Kawasan Kota dengan Peranan Ruas Jalan dalam Sistem Jaringan Jalan Sekunder.

\subsection{Volume Lalu Lintas}

Volume lalu lintas menunjukan jumlah kendaraan yang melintasi satu titik pengamatan dalam satu satuan waktu (hari, jam, menit).Volume lalu lintas adalah banyaknya kendaraan yang melewati suatu titik atau garis tertentu.

\subsection{Tingkat Pelayanan}

Tingkat pelayanan menyatakan tingkat kualitas lalu lintas yang sesungguhnya terjadi.Tingkat ini dinilai oleh pengemudi atau penumpang berdasarkan tingkat kemudahan dan kenyamaan mengemudi.

\subsection{Kapasitas Jalan}

Berdasarkan Manual Kapasitas Jalan Indonesia (MKJI, 1997), perhitungan kapasitas jalan dapat dihitung dengan menggunakan rumus sebagai berikut :

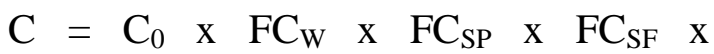
$\mathrm{FC}_{\mathrm{CS}}$ 2.1

Dimana :

$\mathrm{C} \quad=$ Kapasitas (smp/jam)

$\mathrm{C}_{0} \quad=$ Kapasitas dasar (smp/jam) 
$\mathrm{FC}_{\mathrm{W}}=$ Faktor penyesuaian lebar jalan (smp/jam)

$\mathrm{FC}_{\mathrm{SP}}=$ Faktor pemisahan arah (hanya untuk jalan tak berbagi)

$\mathrm{FC}_{\mathrm{SF}}=$ Faktor penyesuaian hambatan samping dan bahu jalan

$\mathrm{FFV}_{\mathrm{CS}}=$ Faktor penyesuaian kecepatan untuk ukuran kota

\subsection{Kecepatan Arus Bebas}

Untuk menentukan besarnya kecepatan arus bebas, dapat ditentukan dengan menggunakan rumus sebagai berikut :

$\mathrm{FV}=\left(\mathrm{FV}_{0}+\mathrm{FV}_{\mathrm{W}}\right) \mathrm{x} \mathrm{FFV}_{\mathrm{SF}} \mathrm{x}$ $\mathrm{FFV}_{\mathrm{CS}}$ 2.2

Dengan :

$\mathrm{FV}=$ Kecepatan arus bebas kendaraan ringan $(\mathrm{Km} / \mathrm{jam})$

$\mathrm{FV}_{0}=$ Kecepatan arus bebas dasar kendaraan ringan $(\mathrm{Km} / \mathrm{jam})$
$\mathrm{FV}_{\mathrm{W}}=$ Penyesuaian lebar jalur lalu lintas efektif $(\mathrm{km} / \mathrm{jam})$

$\mathrm{FFV}_{\mathrm{SF}}=$ Faktor penyesuaian kondisi hambatan samping

$\mathrm{FFV}_{\mathrm{CS}}=$ Faktor penyesuaian ukuran kota

\subsection{Derajat Kejenuhan (Degree of Saturation, DS)}

$\mathrm{DS}=\mathrm{Q} / \mathrm{C}$

Dimana :

DS = Derajat Kejenuhan (DS)

$\mathrm{Q} \quad=$ Volume lalu lintas $(\mathrm{smp} / \mathrm{jam})$

$\mathrm{C} \quad=$ Kapasitas jalan ( $\mathrm{smp} / \mathrm{jam})$

\section{Metode Penelitian}

\subsection{Lokasi Penelitian}

Penelitian analisis kinerja jalan ini dilakukan di Jalan RA Kartini Kota Bandar Lampung.Adapun peta lokasi rencana penelitian ini adalah sebagai berikut .

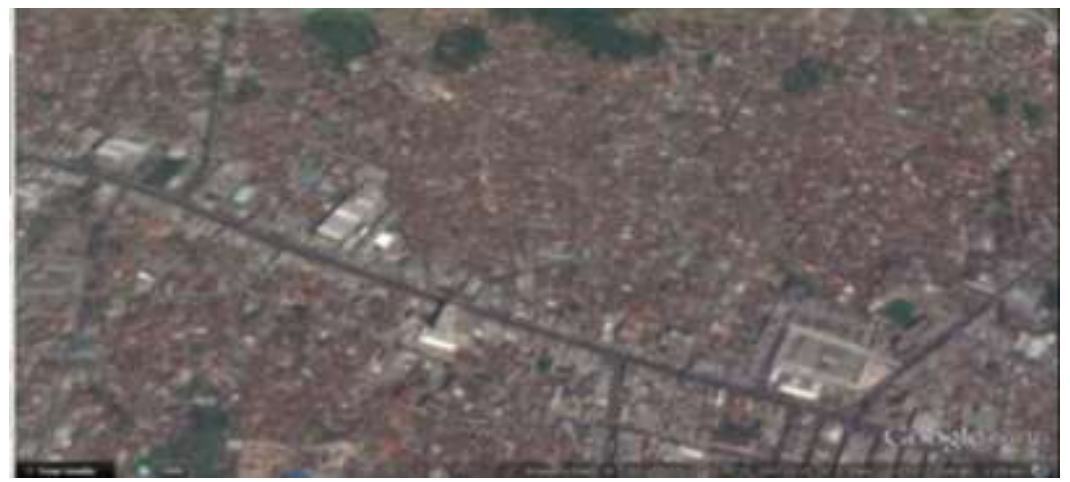

Gambar 1 Peta Lokasi Penelitian (Sumber : Google Map)

\subsection{Sumber Data}

Sumber data yang akan digunakan dalam penyusunan penelitian ini adalah pengumpulan data melalui observasi lapangan dan observasi tidak langsung. Sumber data yang diperoleh penulis dalam penelitian ini berasal dari : 


\subsubsection{Data Primer}

Yaitu data yang diperoleh dengan melakukan survei situasi.

\subsubsection{Data Sekunder}

Yaitu data yang diperoleh dari hasil survei di lokasi penelitian,

\subsection{Tahapan dan Prosedur Penelitian}

Dalam penelitian ini dilakukan tahapanpelaksanaan dan prosedur sebagai berikut :

1. Studi pustaka yaitu mengumpulkan literatur yang berhubungan dengan tugas akhir

2. Melakukan survei dilapangan guna mendapatkan data primer, antara lain: survei volume lalu lintas

3. Menganalisis kapasitas jalan berdasarkan tahapan analisis data (kapasitas jalan, kecepatan arus bebas, derajat kejenuhan, kecepatan dan waktu tempuh).

\section{Hasil Dan Pembahasan}

\subsection{Kondisi Umum Lokasi Penelitian}

Jalan Raden Ajeng Kartini Kota Bandar Lampung termasuk jalan fungsi arteri sekunder dengan kelas Jalan Kota. Panjang jalan ini yaitu $1,20 \mathrm{~km}$ dengan lebar 14 m. Jalan RA Kartini terdiri dari 4 (empat) lajur 1 (satu) arah dengan lebar tiap lajur adalah $3,5 \mathrm{~m}$. Jalan ini tidak memiliki bahu dan hanya di beberapa titik dilengkapi oleh trotoar dengan lebar 1,5 m serta dilengkapi kareb.

\subsection{Perhitungan Kapasitas Jalan}

Perhitungan kapasitas jalan yang dilakukan pada penelitian ini menggunakan rumus sebagai berikut :

$\mathrm{C}=\mathrm{C}_{0} \times \mathrm{F}_{\mathrm{CW}} \times \mathrm{FC}_{\mathrm{SP}} \times \mathrm{FC}_{\mathrm{SF}} \times \mathrm{FC}_{\mathrm{CS}}$

Dengan :

Q maks jalan RA Kartini $=3752,40$ smp/jam

Sehingga berdasarkan data tersebut di atas, dapat diperhitungkan besarnya kapasitas dari jalan RA Kartini adalah sebagai berikut :

$$
\begin{array}{ll}
\mathrm{C} & =\mathrm{C}_{0} \times \mathrm{F}_{\mathrm{CW}} \times \mathrm{FC}_{\mathrm{SP}} \times \mathrm{FC}_{\mathrm{SF}} \times \mathrm{FC}_{\mathrm{CS}} \\
\mathrm{C} & =1650 \times 1,00 \times 1,00 \times 0,89 \times 1 \\
\mathrm{C} & =1486,5 \mathrm{smp} / \mathrm{jam}
\end{array}
$$

Jika diketahui bahwa kapasitas kendaraan pada ruas Jalan RA Katini adalah sebesar 1486,5 smp/jam per lajur. Jika jalan RA Kartini memiliki tipe jalan raya tipe jalan jalan 4 Lajur 1 arah, maka kapasitas totalnya adalah :

C $\quad=4 \times 1486,5=5946 \mathrm{smp} / \mathrm{jam}$

\subsection{Perhitungan Kecepatan Arus Bebas}

Kecepatan arus bebas ditentukan dengan rumus sebagai berikut :

$\mathrm{FV}=\left(\mathrm{FV}_{0}+\mathrm{FV}_{\mathrm{W}}\right) \mathrm{xFC}_{\mathrm{SF}} \times \mathrm{FFV}_{\mathrm{CS}}$ 
Berdasarkan parameter tersebut di atas, diperoleh kecepatan arus bebas di Jalan RA Kartini adalah sebesar :

$\mathrm{FV}=55+0 \times 0,79 \times 1,00$ $=49,5 \mathrm{~km} / \mathrm{jam}$

\subsection{Perhitungan Kecepatan dan Waktu Tempuh}

Kecepatan tempuh didefiniskan sebagai kecepatan rata - rata ruang dari kendaraan ringan (LV) sepanjang segmen jalan, jika diketahui :

$\mathrm{L} \quad=$ panjang segmen jalan RA Kartini $\quad=1,472 \mathrm{~km}$

Untuk menyederhanakan proses analisis, dalam proses perhitungan kecepatan kendaraan, dibagi menjadi 3 segmen, yaitu :

a. Segmen 1 : Tugu Say Batin Simpang Jalan Cut Nyak Dien (Rumah Makan Garuda), panjang jalan $340 \mathrm{~m}$.

- Sehingga kecepatan rata - rata tuang

$$
\begin{aligned}
& \mathrm{LV} \text { adalah }= \\
& \begin{aligned}
\mathrm{V} & =\mathrm{L} / \mathrm{LT} \\
& =0,34 / 0,0228 \\
& =14,912 \mathrm{~km} / \mathrm{jam}
\end{aligned}
\end{aligned}
$$

b. Segmen 2 : Simpang Jalan Cut Nyak Dien - Simpang Jalan Katamso dengan panjang jalan $655 \mathrm{~m}$.

- Sehingga kecepatan rata - rata tuang $\mathrm{LV}$ adalah $=$

$$
\begin{aligned}
\mathrm{V} & =\mathrm{L} / \mathrm{LT} \\
& =0,655 / 0,0867 \\
& =7,555 \mathrm{~km} / \mathrm{jam}
\end{aligned}
$$

c. Segmen 3 : Simpang Jalan Jalan Katamso - Tugu Juang dengan panjang jalan $477 \mathrm{~m}$.

- Sehingga kecepatan rata - rata tuang $\mathrm{LV}$ adalah $=$

$$
\begin{aligned}
\mathrm{V} & =\mathrm{L} / \mathrm{LT} \\
& =0,477 / 0,0311 \\
& =15,337 \mathrm{~km} / \mathrm{jam}
\end{aligned}
$$

Dari hasil perhitungan ketiga segmen di atas dapat dilihat bahwa kecepatan rata rata di jalan RA Katini yaitu berkisar 7,55 $\mathrm{km} / \mathrm{jam}$ - 15,337 km/jam. Hal ini dikarenakan di sepanjang jalan ini banyak terdapat hambatan samping dan pusat perdagangan (pasar bambu kuning), pusat perbelanjaan (Center Point, dan Mall Kartini) dimana pada saat weekend terjadi kemacetan akibat antrian kendaraan yang keluar masuk kawasan tersebut. 


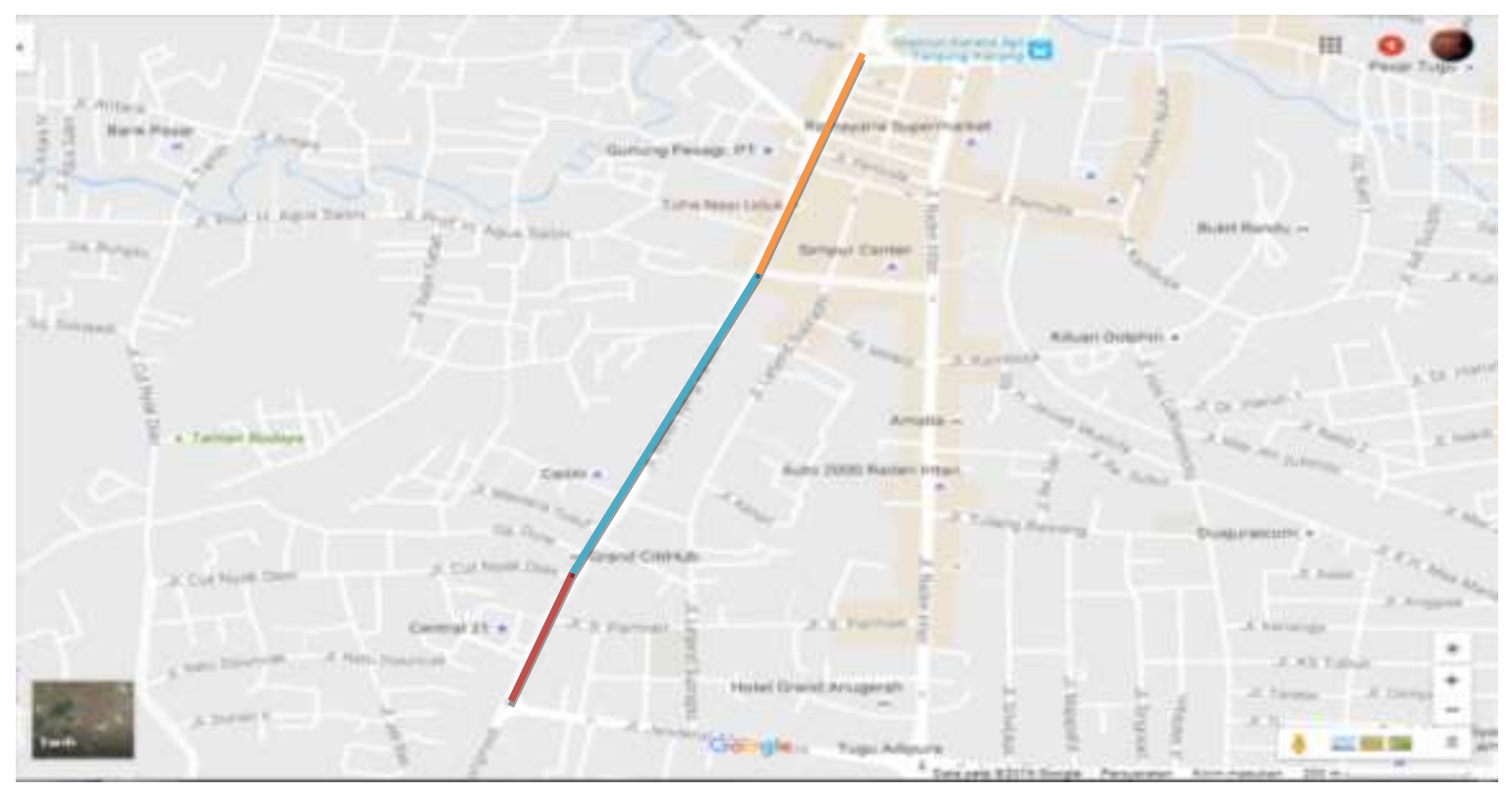

Gambar 4.3 Pembagian Segmen Perhitungan Kecepatan Arus Kendaraan

\subsection{Perhitungan Derajat Kejenuhan (Degree of Daturation)}

Derajat kejenuhan adalah perbandingan dari volume (nilai arus) lalu lintas terhadap kapasitasnya, dengan persamaan sebagai berikut :

$$
\mathrm{DS}=\mathrm{Q} / \mathrm{C}
$$

Dengan :

$$
\begin{array}{ll}
\mathrm{DS} & =\text { Derajat kejenuhan (smp/jam) } \\
\mathrm{Q} & =\text { Arus lalu lintas }(\mathrm{smp} / \mathrm{jam}) \\
\mathrm{C} & =\text { Kapasitas }(\mathrm{smp} / \mathrm{jam}) \\
\mathrm{Ds} & =\mathrm{Q} / \mathrm{C} \\
& =3756,4 / 5946 \\
& =0,632
\end{array}
$$

a. Segmen 2 : Simpang Jalan Cuk Nyak Dien - Jalan, dengan panjang jalan $655 \mathrm{~m}$.

Ds $=\mathrm{Q} / \mathrm{C}$
$=4822,5 / 5946$

$=0,811$

b. Segmen 3 : Jalan Katamso - Tugu Juang, panjang $477 \mathrm{~m}$.

$$
\begin{aligned}
\text { Ds } & =\mathrm{Q} / \mathrm{C} \\
& =2821,1 / 5946 \\
& =0,474
\end{aligned}
$$

Dari hasil perhitungan derajat kejenuhan diperoleh tingkat derajat kejenuhan tertinggi berada pada segmen 2 yaitu sebesar 0,811. Hal ini menandakan bahwa karakteristik Jalan RA Kartini pada saat sibuk pada segmen Simpang Jalan Cut Nyak Dien - Simpang Jalan Katamso berada pada kategori D, yaitu arus mendekati tidak stabil, kecepatan masih dapat dikendalikan, V/C masih dapat ditolerir. 
Hal ini disebabkan pada segmen ini terdapat banyak persimpangan dan persilangan kendaraan yaitu pada simpang Jalan Lindu menuju jalan $\mathrm{S}$ Parman dan Raden Intan, dan Gang Poso.Selain itu pada segmen ini terdapat Mall Kartini dan Hotel Horison, serta pusat perdagangan dimana kemaceta terjadi akibat parkir kendaraan yang keluar masuk di sepanjang jalan ini.

Tabel di bawah ini menunjukkan hasil yang diperoleh dari kajian kinerja jalan protokol RA Kartini Kota Bandar Lampung.

Tabel 9 Hasil Penilaian Kinerja Jalan RA Kartini

\begin{tabular}{|l|l|l|l|l|}
\hline Segmen & Lokasi & Waktu & DS & LOS \\
\hline 1 & Tugu Adat Say Batin - Simpang Jalan Cut Nyak Dien & $15.00-19.00$ & 0,632 & C \\
\hline 2 & Brigjend Katamso - Kamboja & $15.00-19.00$ & 0,811 & D \\
\hline 3 & Kamboja - Bundaran Gajah & $15.00-19.00$ & 0,474 & C \\
\hline
\end{tabular}

Dari tabel diatas dapat kita ketahui bahwa pada waktu $15.00-19.00$ derajat kejenuhan yang paling besar dengan nilai 0,811 ada di lokasi Jalan Brigjend Katamso-Kamboja, sedangkan derajat kejenuhan yang paling kecil adalah Jalan Kamboja-Bundaran Gajah dengan nilai derajat kejenuhan 0,474.

\section{Kesimpulan}

1. Dari hasil perhitungan dapat dilihat bahwa kecepatan rata - rata di jalan RA Katini yaitu berkisar 7,55 $\mathrm{km} / \mathrm{jam}$ - 15,337 km/jam. Hal ini dikarenakan di sepanjang jalan ini banyak terdapat hambatan samping dan pusat perdagangan (pasar bambu kuning), pusat perbelanjaan (Center Point, dan Mall Kartini) dimana pada saat weekend terjadi kemacetan akibat antrian kendaraan yang keluar masuk kawasan tersebut.

2. Dari hasil perhitungan derajat kejenuhan diperoleh tingkat derajat kejenuhan tertinggi berada pada segmen 2 yaitu sebesar 0,811 . Hal ini menandakan bahwa karakteristik Jalan RA Kartini pada saat sibuk pada segmen Simpang Jalan Cut Nyak Dien - Simpang Jalan Katamso berada pada kategori D, yaitu arus mendekati tidak stabil, kecepatan masih dapat dikendalikan, V/C masih dapat ditolerir.

\section{Daftar Pustaka}

Clarkson H.O dan Gerry, 1988, Teknik Jalan Raya Edisi Kedua, Jakarta

Dinas Perhubungan DKI Jakarta, 2003.Survei Lalu Lintas Wilayah 
DKI Jakarta dan Bekasi, Pemerintah Provinsi DKI Jakarta.

Direktorat Jenderal Bina Marga, 1997.

Manual Kapasitas Jalan

Indonesia, Dinas Pekerjaan

Umum.

Ikarini, 2010. Analisis hambatan samping jalan Protokol Kota Bandar Lampung, Universitas Lampung, Bandar Lampung.

Morlock Edward K, 1991. Pengantar

Teknik dan Perencanaan

Transportasi

Soehodho dan Stutanto, 1998. Rekayasa

Lalu Lintas, Departemen

Pendidikan dan Kebudayaan,

Cisarua, Bogor.

Peraturan Pemerintah No. 34 Tahun 2006 